painted a vivid picture of this kind of pain, but after a short period, by control of infection and the use of steroids, pain was controlled. The point is that you can relieve pain so that a person is himself. To be able to go to the theatre two nights before you die is the kind of thing we should have as our aim, wherever it is possible.

So much pain can be relieved without resorting to analgesics. The doctor must sit and listen to the various facets of distress so that he may see whenever something specific or some new adjuvant can be introduced. Nor do we need to employ large doses if drugs are given regularly. The maximum doses needed by the majority of our patients are not high. Out of a total of 500 patients 428 were given diamorphine for control of pain. Only $19 \%$ ever needed more than $20 \mathrm{mg}$ at a time.

\section{Involving the Whole Family}

If the patient has to come into hospital I do think it is of enormous importance that the family should feel as if they come in as a whole. Sometimes one enables people to meet again. One family I remember was reunited in this way. The sons met their father again, when at home they had been refusing to speak to him, resentful and uncomfortable with the illness of which they were so frightened: the fits, the strangeness. And in the hospital atmosphere the wife and the mother-in-law also began to be able to talk and work through some of their feelings. Rather later in this patient's illness, not very long before he died, he enjoyed the sort of visiting that one wants; like one's time together at home, the family just sitting reading the paper, the wife knitting, the informality and being relaxed. That wife was able to wash her husband and do a lot of things for him in the ward. We know something of this family and the stresses of their bereavement. The boys got very aggressive with each other. One thought he had a cerebral tumour and the mother, now a widow, had to call the doctor in the night. But now one is married, one is in the Air Force, and the third, having failed his $O$ levels at the time of his father's illness, has taken them again and passed. As for the wife, she has been coming back to us as a volunteer.

Children should visit, should be involved, should be part of what is happening. But to do that we must be able to control pain; it must be the father they know. And in doing this we have to learn when to stop doing our prolongation and when we accept that this is a peaceful death and should be allowed to happen. It is far better to have a cup of tea on your last day than drips and tubes in every direction. And I think this cup of tea comes best of all from someone who has compassion, understanding, and practicality-someone who does add heart to skill and has a sense of meaning and assurance of another dimension in life. We should never impose our own beliefs and own feeling of meaning on to another person, but I am quite sure we could help produce a climate in which the patients can find their own meanings, and can find the quietness and dignity of death as it can be when it is a person not the apparatus around that is the centre of attention.

Finally, I remember a patient not with cancer but with motor neurone disease, a police sergeant who died aged 39 after 2 to 3 years of illness. I remember his saying at an early stage, "If I thought I'd ever be like that chap I'd do something to myself." But when he did reach the stage that he had been watching he found that, from inside, the situation was very different as long as he was not alone. We often discussed talks such as this and he once offered me a title, "Bringing-together Illness," in preference to the phrase "Catastrophic" or "Terminal" which I had been given. I said, "Do you always see this "bringingtogether' happen ?" He said "Yes, I am a trained observer and I've been here for 18 months. Patient and family, patient and staff, patient and patient-yes it does happen." And he went on making this more true to himself up to the very end. I remem- ber his saying, "I can't see round the next bend but I know it'll be all right." What we have to try to do, I think, is somehow to help the dying patient and his family in every possible way to find this kind of security. The world in which your own body is letting you down, and the world in which someone has left you, feels and sometimes is a very unsafe place. But this situation which cannot be changed can be transformed. The demands of the family are in many ways the same as those of the patient. They do not need just sympathy and sedatives, but something that was summed up for us for all time with for all with the words "Watch with Me." I think that phrase means listening without necessarily knowing the answers, and persevering with the practical, which includes developing skills. But above all it means do not forget to be simple; be prepared just to be there. We must somehow give everything that we can to these people that says "you matter because you are you," everything to enable the patient to live up until he dies, and the family to go on living afterwards.

St. Christopher's Hospice, London S.E.26

CICELY SAUNDERS, O.B.E., M.R.C.P., Medical Director

\section{A Death in the Family: A Professional View}

\section{W. FERGUSON ANDERSON}

The public require reassurance, in that people in general are worried about the process of dying. Individuals do not fear death but how they will die with the attendant problems. Cramond ${ }^{1}$ believed that seriously ill patients did think of death as a possible outcome, often welcomed the chance to talk about their feelings, but were concerned mainly about the way in which dying would occur. In general people do not understand what goes on in a hospital-particularly when a person diesand there is concern about the belief that old people are kept alive unnecessarily. Reassurance is therefore required that in fact old people are not kept alive, and the act of dying is not prolonged. The B.M.A. panel on euthanasia in 1970 felt that the argument that the elderly are kept alive by drugs had been grossly exaggerated and that old people benefited more from kindness, good nutrition, and good nursing.

In the hands of experienced doctors people towards the end of their lives are kept free from distressing symptoms such as thirst and from pain and discomfort. Much more explanation and communication with relatives as to what the present therapeutic regimen is about is necessary. The subcutaneous saline drip which is being given to alleviate symptoms of dry mouth and thirst is not prolonging the patient's life unnecessarily, but relieving uncomfortable and worrying symptoms. Though services for the elderly in hospital have improved and more consultant appointments have been made, it is still the young doctor, very often newly qualified, who is asked about the present condition of a very old person, usually supported by the experienced and well-trained sister. In our new planning we must try and provide time for the senior doctor to interview the relatives of those who are ill and need explanation and reassurance. Gibson ${ }^{2}$ showed the great value and benefit when elderly people die in their own homes, and here again public reassurance is required that when the social circumstances permit domiciliary services should be adequate to enable the relatives to play a full part in the care of the dying patient without being pushed over the edge into breakdown. Lastly, our social conscience demands that when the general practitioner requires the admission of his dying patient to a hospital, accommodation of desirable amenity 
should be available, with nursing staff trained for such an eventuality. It must be emphasized that the hospital is not the only provision for this sort of patient and fortunately many voluntary agencies provide a similar service. My own view is that the wider the spectrum of services available, the more likely the patient through his general practitioner is to get help appropriate to his need.

\section{Personal Care}

When the personal care of the individual is concerned there are three issues. The first is that the correct diagnosis must be made -in other words, if the patient is being treated as if he were dying then in fact he must be dying. In many instances clear-cut presentation is there-there is no doubt that the individual has reached the end of his life-but there are patients on whom a label of a certain illness is placed and on occasion this may be wrong, so it is essential that the physician seeing a patient for the first time with a diagnosis already fixed should review this with care and detail to satisfy himself about the diagnosis.

The second consideration is the relief of pain, and other worrying symptoms, and great attention must be paid to the minor complaints of individuals who are reckoned to be in their last illness, and Dr. Saunders ${ }^{3}$ has always stressed these points. In fact, once the diagnosis has been established, that the patient is indeed dying, the therapy, though requiring review and alteration, must nonetheless be thorough. Time must be found to talk with such patients, to listen to their complaints, worries, and requests. Their symptoms must be treated, adequate fluid intake ensured, bowel regulation without discomfort achieved, electrolyte imbalance corrected. These procedures are not directed to dragging out a life already lost, but to the complete necessity for rendering the individual comfortable, and here the nurses require the doctor's guidance. They require advice on clinical day-to-day management, and they need encouragement and sustenance to their own mental health, which may be in some risk because of the nursing of such people. For the young nurse there may be a high degree of emotional involvement and she may require detailed and kindly explanation as to why the individual whom she likes and nurses is unable to get well. She may also require explanation about measures which are being undertaken which she thinks, albeit wrongly, are prolonging the patient's life unnecessarily.

Cramond ${ }^{1}$ believed that, when there is a very close relationship between patient and doctor, the doctor should give the patient a lead-in, in that he may be able to express his worries and doubt and to ask questions whether in fact he is dying. He stressed the need for training of personnel with regard to this situation. If, bearing in mind a full consideration of the patient's physical and psychological make-up and his best interests, it has been agreed that there should be a conspiracy of silence, then without consultation no well-meaning friend or relative should take it on himself or herself to tell the patient the whole truth, with the patient being unprepared, unexpecting, and unwanting to receive $s_{i}$ th information. For staff education we require training and explanation of each stage of therapy. We need to instruct our staff in the ability to communicate with relatives, visitors, and the clergy, and we need to encourage an enthusiastic outlook on pain-relieving therapy, and vigilance in the detection of discomfort and distressing symptoms.

\section{Support for the Bereaved}

The best person to give immediate comfort for those bereaved is almost certainly the family doctor, acting in co-operation and with the help of the priest or clergy if this is desired. Studying the effect of bereavement on elderly people as a health visitor, Wilson postulated that this is a time when a continuing contact with a skilled visitor such as the health visitor is of the utmost importance. After bereavement the older person generally tends to withdraw from friends and society. Wilson thinks that a most effective method of preventing social isolation and loneliness in old people is through support given at the time of greatest grief, encouraging the intake of adequate diet, and ensuring that they do not become completely cut-off from their families, friends, and neighbours, and that some interest is found for them. She felt that there should be a list kept of elderly people living together, so that if one became ill a watch could be kept; if bereavement occurred health visiting of the remaining elderly person would take care immediately. Numerous studies have shown the deleterious effect of bereavement on older people's mental health.

Time is the great healer, but during this hard phase of life every effort must be made to prevent a turning away from everyday matters and the feeling of hopeless depression.

\section{References}

1 Cramond, W. A., British Medical fournal, 1970, 3, 389.

2 Gibson, R., Fournal of the Royal College of Physicians of London, 1971, 5, 135.

3 Saunders, C., Proceedings of the Royal Society of Medicine, 1963, 56, 195. 4 Wilson, F. G., Lancet, 1970, 2, 1356.

\section{University of Glasgow}

W. FERGUSON ANDERSON, O.B.E., M.D., F.R.C.P., David Cargill Professor of Geriatric Medicine

\section{Where to Die}

\section{E. WILKES}

I am fond of saying that the two commonest diagnoses in general practice are the fear of life and the fear of death, and that, surprisingly and rather pathetically, the fear of life is the more common. The fear of death and the fear of dying can be a heavy, indeed a disabling, burden. This is natural; one cannot separate society from the medicine that serves that society. And our society has an uncertain and insecure attitude to death and to dying because we are a world removed from the farm-yard realities of birth and life and death. Indeed, in one survey only $15 \%$ of medical professional workers in training had, before their training, ever seen anyone die. And this partly is what all the fuss is about. The reasons for this are of course social. We have changed the causes of death, the type of dying, the place of dying, and the age of dying. Naturally, therefore, the medical and nursing professions, despite their centuries of involvement in these sorts of problems, are feeling somewhat inadequate and in need of a reassessment of their role and of the situation.

In my own practice we found that no less than $68 \%$ of deaths were consequent on a slow and tedious illness which on purely clinical grounds we classed as overdue. And in a society in which small houses and the part-time job are part of the pattern of life, this obviously produced special stress and special strain. The place of dying is therefore not unconnected with the problems of the terminal illness, and we have seen a great expansion in this country of dying in an institution. In my own area a few years ago we found that $55 \%$ of cancer deaths occurred at home, but about a third died in an acute hospital bed and about $10 \%$ in the long-stay geriatric units. We are obviously getting towards the New York State situation, where less than a quarter of all deaths occur at home. Moreover, of the half million deaths each year in the British Isles half take place at over 75 years of age, over 90,000 at over 85 years of age, and over 500 at over 100 years of age. So the magnitude as well as 